DOI: https://doi.org/10.15688/jvolsu3.2018.2.11

UDC 62-405.(045)

LBC 65.28

\title{
ASSESSMENT OF THE EFFICIENCY OF THE REGIONAL SYSTEM FOR WASTE MANAGEMENT
}

\author{
Alla E. Kalinina \\ Volgograd State University, Volgograd, Russian Federation \\ Anna S. Barakova \\ Volgograd State University, Volgograd, Russian Federation
}

\begin{abstract}
As a result of comparative analysis of statistical data on the amount of waste and storage areas in the territory of the Volgograd region, it is revealed that to date, there is an increase in the share of used, recycled wastes in the total volume of generated production and consumption wastes. However, the regional waste management system does not ensure a complete clean-up of the territory and effective implementation of activities in this area. The Volgograd region is characterized by significant anthropogenic pressures on regional components of the environment, which are caused by intensive activities of many industrial enterprises and transport. The main trends observed in the sphere of waste management in the region are a steady increase in the volume of waste generation, followed by their placement in landfills and unauthorized dumps; pollution of the environment with industrial, communal and agricultural wastes. There are practically no capacities and technologies in the region for the involvement of waste in economic circulation. The identified peculiarities and problems in the organization of waste processing actualize the need to develop the measures on improving the waste management system in the region: the combination of direct and two-stage waste removal, the exclusion of storage of unsorted waste at landfills, the reconstruction of container sites and the development of a container and garbage park, the construction of waste sorting/garbage processing complexes, in connection with the increase in the volume of production and consumption wastes, which remains one of the main environmental problems in the Volgograd region.
\end{abstract}

Key words: regional economy, ecology, solid domestic waste, waste treatment, environment.

УДК 62-405.(045)

\section{ОЦЕНКА ЭФФЕКТИВНОСТИ ОРГАНИЗАЦИИ РЕГИОНАЛЬНОЙ СИСТЕМЫ ПЕРЕРАБОТКИ ОТХОДОВ ${ }^{1}$}

Алла Эдуардовна Калинина

Волгоградский государственный университет, г. Волгоград, Российская Федерация

Анна Сергеевна Баракова

Волгоградский государственный университет, г. Волгоград, Российская Федерация

Аннотация. В результате компаративного анализа статистических данных по количеству отходов и мест их складирования на территории Волгоградской области выявлено, что на сегодняшний день наблюдается 
увеличение доли использованных переработанных отходов в общем объеме образовавшихся отходов производства и потребления. Однако, региональная система переработки отходов не обеспечивает полной очистки территории и эффективного проведения мероприятий в данной сфере. Волгоградская область характеризуется значительными антропогенными нагрузками на региональные компоненты окружающей среды, которые обусловлены интенсивной деятельностью многих промышленных предприятий и транспорта. Основные тенденции, наблюдаемые в сфере обращения отходов в регионе, - это неуклонный рост объемов образования отходов с последующим их размещением на полигонах и несанкционированных свалках; загрязнение окружающей среды отходами промышленности, коммунального и сельского хозяйства. В области практически отсутствуют мощности и технологии по вовлечению отходов в хозяйственный оборот. Выделенные особенности и проблемы в организации переработки отходов актуализируют необходимость разработки мер по совершенствованию системы обращения с отходами в регионе: сочетание прямого и двухэтапного вывозов отходов, исключение складирования несортированных отходов на полигонах, реконструкция контейнерных площадок и развитие контейнерного и мусоровозного парка, строительство мусоросортировочных/мусороперерабатывающих комплексов, в связи с увеличением объема отходов производства и потребления, что остается одной из основных экологических проблем в Волгоградской области.

Ключевые слова: региональная экономика, экология, твердые бытовые отходы, переработка отходов, окружающая среда.

Современная система обращения с отходами в Российской Федерации включает определенный спектр действий и операций, а также характеризуется взаимодействием с хозяйствующими субъектами. Субъектами могут являться государственные и муниципальные предприятия, частные предприятия и предприятия-производители. На сегодняшний день, преобладающим способом обращения с отходами является их утилизация на полигонах путем складирования и захоронения. Современные реалии заставляют искать другие подходы, удовлетворяющие вопросам устойчивого развития и «зеленой» экономики, требованиям качественного обращения с отходами, использования вторичного сырья на основе выделения полезного компонента.

Реализация программ, направленных на утилизацию, переработку, обезвреживание и вторичное использование образующихся и накопленных отходов с выработкой дополнительной электрической и тепловой энергии актуальна, практически для всех отраслей промышленности. По экспертным оценкам в настоящее время на территории РФ накоплено свыше 120 млрд тонн отходов, и их накопление продолжается (20 млн тонн в год - выбросы в атмосферу и 80 млн тонн в год - твердые и жидкие отходы) [3, с. 43]. Для обеспечения эффективного и экологически безопасного решения проблем обращения с отходами важен выбор оптимальных инновационных современных технологий, позволяющих значительно уменьшить объем накопленных заг- рязнений, придать им форму, удобную для хранения и безопасную для окружающей среды, извлечь содержащиеся в них полезные компоненты и вещества и использовать энергию, выделяющуюся при переработке.

Вопросы переработки отходов во вторичное сырье становятся все более важными для мировой экономики. На сегодняшний день, активно проектируются и строятся предприятия замкнутых циклов движения отходов и безотходные производства, которые позволяют извлекать из сырья все необходимые полезные составляющие. Хотя, в течение последних 30 лет вблизи крупных промышленных предприятий и городов происходило складирование всевозможных отходов производства и потребления, которое негативно сказывается на состоянии окружающей среды и здоровье людей.

В Российской Федерации общий объем твердых бытовых отходов (ТБО) составляет приблизительно 35-40 млн тонн в год [5, с. 9]. В основном, в состав ТБО входит большое количество компонентов, которые можно повторно использовать после сортировки и тщательной переработки. Большее количество таких отходов образуют пластмассы, стекло и прочие синтетические материалы, так как они не разрушаются биологическим путем и могут долгое время находиться в должном качестве в природе.

Главный фактор, оказывающий влияние на характер управления твердыми бытовыми отходами любого города России, - нормы накопления ТБО. Объективно, имея исключи- 
тельно достоверную информацию о накоплении в населенном пункте отходов можно точно планировать цепочку движения отходов до его утилизации [7, с. 35].

Низкий уровень вторичной переработки в России связан с тем, что далеко не везде есть необходимые для нее технологии и квалифицированные кадры, а также с тем, что на данном этапе в ней нет острой нужны, так как территория страны позволяет осуществлять менее затратное и более привычное захоронение, а достаточно богатые природными ресурсами территории позволяют пренебрегать вторсырьем и продолжать добывать полезные ископаемые.

Волгоградская область характеризуется значительными антропогенными нагрузками на региональные компоненты окружающей среды, которые обусловлены интенсивной деятельностью многих промышленных предприятий и транспорта.

Основные тенденции, наблюдаемые в сфере обращения отходов в регионе, - это неуклонный рост объемов образования отходов с последующим их размещением на полигонах и несанкционированных свалках; загрязнение окружающей среды отходами промышленности, коммунального и сельского хозяйства. В области практически отсутствуют мощности и технологии по вовлечению отходов в хозяйственный оборот. При этом недостаточны меры государственного регулирования в сфере обращения с отходами, не учитывается потенциал накопленных отходов, являющихся вторичными ресурсами.

Для координации деятельности и формирования системы управления в сфере обращения с отходами, создана межведомственная комиссия по вопросам обращения с отходами на территории области, в состав кото- рой вошли руководители природно-ресурсных и контрольно-надзорных органов. Практическими результатами деятельности комиссии является оказание содействия муниципальным районам по отводу земельных участков под размещение ТБО, оформление градостроительных планов и обеспечение долевого участия в финансировании.

Хотя на территории области и действуют организации, осуществляющие сбор, переработку некоторых видов отходов, системный раздельный сбор отходов практически отсутствует. Большая их часть отправляется на свалки. Причина - низкая информированность населения и организаций о существовании таких предприятий и нежелание заниматься сбором и сдачей отдельных видов отходов перерабатывающим предприятиям, имея при этом небольшую материальную выгоду [4, с. 10].

Наибольшее количество отходов образующихся в Волгоградской области - это отходы IV и V классов опасности (см. таблицу). Это связано с большим количеством производств, строительных работ, а также достаточно большим количеством населения в городах. К тому же, наблюдается достаточно низкий уровень наиболее опасных отходов, что связано с закрытием сразу нескольких заводов на территории Волгоградской области, однако, общее количество этих отходов существенно не изменяется вследствие усиленной деятельности оставшихся заводов.

Источниками образования отходов на территории Волгоградской области являются: добывающая промышленность, цветная и черная металлургия, лесная и химическая промышленность, энергетика, легкая и пищевая промышленность, также жилищный фонд, хозяйственные и общеобразовательные учреждения, торговые и спортивные предприятия,

Таблица

Динамика образования отходов в Волгоградской области за 2009-2016 гг., тыс. тонн

\begin{tabular}{|l|c|c|c|c|c|c|c|c|}
\hline \multicolumn{1}{|c|}{ Наименование } & $\mathbf{2 0 0 9}$ & $\mathbf{2 0 1 0}$ & $\mathbf{2 0 1 1}$ & $\mathbf{2 0 1 2}$ & $\mathbf{2 0 1 3}$ & $\mathbf{2 0 1 4}$ & $\mathbf{2 0 1 5}$ & $\mathbf{2 0 1 6}$ \\
\hline Всего отходов & 1459 & 1181 & 872 & 2134 & 2797 & 2489 & 3955 & 3829,2 \\
\hline I класс опасности & 3,5 & 2,9 & 0,6 & 0,7 & 0,9 & 8,1 & 12,9 & 10,2 \\
\hline II класс опасности & 5,2 & 5,2 & 5,3 & 8,8 & 4,9 & 0,5 & 3,8 & 3,4 \\
\hline III класс опасности & 508 & 54,9 & 513,5 & 552,5 & 183,3 & 70,9 & 170,6 & 160,6 \\
\hline IV класс опасности & 615 & 689 & 246,7 & 1219 & 1796 & 1631 & 1939 & 1920 \\
\hline V класс опасности & 331 & 428,9 & 105,9 & 353,2 & 802,9 & 779,1 & 1828 & 1735 \\
\hline
\end{tabular}

Примечание. Составлено автором по: [2; 4; 6]. 
накапливаются отходы от «зеленого» фонда и ремонтных работ.

Стоит отметить, что некоторое количество отходов передается на другие предприятия, где их могут использовать. Так реализуется вторичное обращение с отходами, однако, подобное обращение практически невозможно с опасными отходами.

В каждом районе Волгоградской области есть свалки твердых коммунальных отходов (ТКО), однако практически нигде нет полигонов ТКО, в первую очередь это говорит о том, что твердые коммунальные отходы в большинстве районов, кроме Светлоярского, а также г. Камышин, г. Волжский и г. Волгоград хранятся, с большой долей вероятности, нанося вред окружающей среде, так как свалки не обустроены должным образом. Нельзя не отметить отсутствие полигонов промышленных отходов на территории области, кроме крупных городов, таких как г. Камышин, г. Михайловка и г. Волжский. Возможно, подобные полигоны там отсутствуют за ненадобностью, ведь промышленных предприятий в большом количестве в районах нет. Однако это не говорит о полном отсутствии промышленных отходов, которые там, естественно, есть. В результате, промышленные отходы попадают либо на полигоны ТКО, либо в окружающую среду.

На территории Волгоградской области насчитывается порядка 4000 мест централизованного сбора ТКО (контейнерных и бункерных площадок для тарного способа сбора отходов), более половины которых расположены в г. Волгоград и г. Волжский.

Территориальной схемой удаления твердых коммунальных отходов с территорий населенных пунктов Волгоградской области, утвержденной приказом комитета природных ресурсов и экологии Волгоградской области от 28 авг. 2015 г. № 807 (ред. от 14 дек. 2015 г.), предусмотрено создание площадок временного накопления отходов, соответствующих требованиям санитарно-эпидемиологического и природоохранного законодательства. В 2016 г. обустроены и введены в эксплуатацию 6 площадок, в том числе 1 в Иловлинском (р.п. Иловля), 1 в Николаевском (г. Николаевск), 1 в Ольховском (с. Ольховка), 3 в Октябрьском (р.п. Октябрьский, с. Аксай, с. Громославка) муниципальных районах. Отходы с данных площадок транспортируются на полигоны ТКО [4, с. 172]. В 2017 г. на территории полигона ООО «Комус» в Светлоярском районе Волгоградской области и на территории, прилегающей к полигону ООО «Экомастер» в пос. Гумрак за счет внебюджетных средств построены мусоросортировочные линии, осуществляющие сортировку отходов, вывозимых с территории г. Волгограда.

В решении проблем обращения с отходами применяется программно-целевой подход. Его суть заключается в выделении направлений и формировании плановых показателей в области обращения с отходами, а также разработке мероприятий по их достижению. Для осуществления данного подхода были приняты программы федерального и регионального уровня. Так, для предприятий, вошедших в территориальную схему размещения объектов приема ТБО и планируемых к созданию, подготовлена и утверждена подпрограмма «Обращение с твердыми коммунальными отходами на территории Волгоградской области», которая 11 июля 2014 г. вошла в состав государственной программы Волгоградской области «Охрана окружающей среды на территории Волгоградской области» на 2014-2020 гг., утвержденной постановлением Правительства Волгоградской области от 4 дек. 2013 г. № 686-п.

На территории Волгоградской области 178 организаций, занимающихся сбором и транспортировкой ТБО, имеют действующую лицензию. Наиболее востребованной является «Сфера Чистоты», что связанно с удобным расположением в г. Камышин и развитой транспортной сетью. В г. Волгоград и близлежащих районах основной организацией в данной сфере является «Комус», что, скорее всего, связано с наличием собственного лицензированного полигона. Все остальные полигоны не имеют лицензии на хранение и размещение отходов, а значит, любая их деятельность в данной сфере незаконна. Однако далеко не все отходы можно использовать и обезвреживать, поэтому необходимы лицензированные полигоны для их размещения и утилизации.

Также необходимо отметить, что региональная система переработки отходов не 
обеспечивает полной очистки территории и эффективного проведения мероприятий в данной сфере. Поэтому комитет охраны окружающей среды и природопользования Администрации Волгоградской области на регулярной основе осуществляет работу по предупреждению и ликвидации несанкционированных свалок, созданию объектов инфраструктуры TКО, а также мероприятия, направленные на организацию раздельного сбора отходов, например: проводятся рабочие встречи с администрациями муниципальных образований по вопросам недопущения образования несанкционированных свалок, на которых выясняются главные причины негативной ситуации и вырабатываются пути решения данного вопроса; на постоянной основе осуществляется системная работа регионального государственного экологического надзора - рейды, ежегодные операции «Отходы»; размещается информация в сфере обращения с отходами на официальном портале губернатора и Администрации Волгоградской области в целях повышения экологической образованности и культуры населения в сфере обращения с отходами.

Основные причины сложившейся негативной обстановки на территории Волгоградской области заключаются в следующем: несовершенное законодательство Волгоградской области в сфере обращения с отходами; низкая культура населения; отсутствие полигонов по размещению и захоронению ТБО, отвечающих санитарно-гигиеническим требованиям; отсутствие современной промышленной базы по переработке твердых бытовых и промышленных отходов; недостаточность средств на строительство новых полигонов в областном и местных бюджетах.

Для решения существующих проблем была разработана долгосрочная муниципальная целевая программа «Чистый Волгоград» на 2012-2018 гг., которая является своего рода продолжением реализуемой ранее программы. Целью программы является внедрение эффективной системы обращения с отходами производства и потребления, оптимизация системы сбора и вывоза ТБО на территории г. Волгограда. Исполнителем-координатором программы был назначен департамент по охране окружающей среды и природных ресурсов администрации г. Волгограда (сегодня - Комитет благоустройства и охраны окружающей среды), который несет ответственность за своевременную и эффективную реализацию мероприятий программы и осуществляет контроль за ходом ее реализации.

По итогам реализации программы «Чистый Волгоград», в ходе проведения аудита эффективности реализации муниципальных целевых программ, установлено неэффективное использование бюджетных средств в размере 4 525,0 тыс. руб. Следовательно, pеализация программы осуществляется не по плану и запланированные мероприятия проводятся недостаточно эффективно [1]. При этом фактически выполняются лишь те мероприятия (за счет средств местного бюджета и средств промышленных предприятий), которые выполнялись и до принятия программы в соответствии с действующим законодательством. Также, предусмотренная программой задача внедрения раздельного сбора отходов населения в настоящее время не выполнена.

Показатели программы «Чистый Волгоград» являются детализацией «Стратегического плана устойчивого развития Волгограда до 2025 г.», принятого Волгоградской городской Думой 24 декабря 2007 года. В данном документе рассмотрены все компоненты устойчивого развития, в том числе и окружающая среда, в которую входит такой подпункт как отходы. Следует отметить, что показатели указанной программы имеют более широкий спектр и охватывают не только вопросы обращения с отходами, но и социально-экономические аспекты.

На сегодняшний день наблюдается увеличение доли использованных переработанных отходов в общем объеме образовавшихся отходов производства и потребления до $10 \%$, в то время, как, согласно стратегическому плану, к 2025 г. этот показатель должен достигать $60 \%$, что говорит о низкой эффективности реализации запланированных мероприятий по развитию региональной системы переработки отходов. По итогам реализации стратегического плана на конец 2017 г., можно отметить, что уровень достижения индикаторов стратегической цели - средний. 
Бесспорно, на данном этапе социально-экономического развития общества стоит делать акцент на вторичное использование отходов и выделение из них полезного компонента [8, с. 3]. Это не только поможет сократить количество отходов в окружающей среде, но и существенно сэкономит имеющиеся ресурсы, что благоприятно для экономики региона. Однако данный вариант обращения с отходами слабо развит на территории г. Волгограда и Волгоградской области, более того, в «Стратегическом плане устойчивого развития Волгограда до 2025 г.» о вторичном обращении с отходами вообще не говорится, хотя этот вопрос затрагивается в программе «Чистый город».

Полученные результаты актуализируют необходимость разработки мер по совершенствованию системы обращения с отходами в регионе: сочетание прямого и двухэтапного вывозов отходов, исключение складирования несортированных отходов на полигонах, реконструкция контейнерных площадок и развитие контейнерного и мусоровозного парка, строительство мусоросортировочных/мусороперерабатывающих комплексов, в связи с увеличением объема отходов производства и потребления, что остается одной из основных экологических проблем в Волгоградской области.

Таким образом, перспективное направление развития региональной системы переработки отходов - это вовлечение отходов в производственный процесс по следующим ключевым направлениям: раздельный сбор отходов, мусоросортировка, извлечение полезного компонента и вторичное использование ресурсов.

\section{ПРИМЕЧАНИЕ}

${ }^{1}$ Исследование выполнено при финансовой поддержке РФФИ, проект № 17-12-34008 «Организация эффективной региональной системы обращения с отходами и ее инфраструктуры: институциональный, экономический и правовой аспект».

\section{СПИСОК ЛИТЕРАТУРЫ}

1. Аудит эффективности реализации муниципальных целевых программ // Контрольно-счетная палата Волгограда. - Электрон. текстовые дан. - Режим доступа: http://www.kspvolg.ru/Services/ analit.aspx?artmod (дата обращения: 16.03.2018). Загл. с экрана.

2. Волгоградская область в цифрах : Стат. сб. Волгоград : Волгоградстат, 2017. -С. 128.

3. Волынкина, А. П. Анализ состояния и проблем переработки техногенных отходов в России / А. П. Волынкина // Вестник Сибирского государственного индустриального университета. № 2 (20). - 2017. - С. 43-49.

4. Доклад «О состоянии окружающей среды Волгоградской области 2016 году» / ред. колл. : П. В. Вергун [и др.] ; комитет охраны окружающей среды и природопользования Волгоградской области. - Волгоград : «СМОТРИ», 2017. - 300 с.

5. Отходы в России: мусор или ценный ресурс? Сценарии развития сектора обращения с твердыми коммунальными отходами. - М. : Международная финансовая корпорация, 2013. - 90 с.

6. Регионы России. Социально-экономические показатели : Стат. сб. - М. : Росстат, 2017. -С. 694.

7. Хандагина, Б. К. Экологические основы природопользования / Б. К. Хандагина. - М. : ФОРУМ ; ИНФРА-М, 2011. - 160 с.

8. Li, R.Y. M. Construction safety and waste management: an economic analysis / R.Y. M. Li. Switzerland: Springer International Publishing, 2015. - P. 2-4.

\section{REFERENCES}

1. Audit effektivnosti realizatsii munitsipalnykh tselevykh programm [Audit of the Effectiveness of Municipal Target Programs]. Kontrolno-schetnaya palata Volgograda [Control and Accounting Chamber of Volgograd]. URL: http://www.kspvolg.ru/Services/ analit.aspx?artmod (accessed 16 March 2018)

2. Volgogradskaya oblast $v$ tsifrakh. Statisticheskiy sbornik [The Volgograd Region in Figures. Statistical Collection]. Volgograd, Volgogradstat Publ., 2017, p. 128.

3. Volynkina A.P. Analiz sostoyaniya i problem pererabotki tekhnogennykh otkhodov v Rossii [Analysis of the Condition and Problems of Industrial Wastes Processing in Russia]. Vestnik Sibirskogo gosudarstvennogo industrialnogo universiteta, 2017 , no. 2 (20), pp. 43-49.

4. Vergun P.V., et al. (eds.) Doklad «O sostoyanii okruzhayushchey sredy Volgogradskoy oblasti 2016 godu» [Report 'On the Condition of the Environment of the Volgograd Region in 2016]. Committee for Environmental Protection and Nature Management of the Volgograd Region. Volgograd, SMOTRI Publ., 2017. 300 p.

5. Otkhody v Rossii: musor ili tsennyy resurs? Stsenarii razvitiya sektora obrashcheniya s tverdymi kommunalnymi otkhodami [Wastes in Russia: 
Garbage or a Valuable Resource? Scenarios for the Development of the Sector for Solid Domestic Waste Management]. Moscow, International Finance Corporation, 2013.90 p.

6. Regiony Rossii. Sotsialno-ekonomicheskie pokazateli [Regions of Russia. Social and Economic Indicators]. Moscow, Rosstat Publ., 2017. 694 p.
7. Khandagina B.K. Ekologicheskie osnovy prirodopolzovaniya [Ecological Basics of Nature Management]. Moscow, FORUM; INFRA-M Publ., 2011. 160 p.

8. Li R.Y.M. Construction Safety and Waste Management: An Economic Analysis. Switzerland, Springer International Publishing, 2015, pp. 2-4.

\section{Information about the Authors}

Alla E. Kalinina, Doctor of Sciences (Economics), Professor, Department of Applied Informatics and Mathematical Methods in Economics, Volgograd State University, Prosp. Universitetsky, 100, 400062 Volgograd, Russian Federation, allakalinina@volsu.ru.

Anna S. Barakova, Student, Institute of Economics and Finance, Volgograd State University, Prosp. Universitetsky, 100, 400062 Volgograd, Russian Federation, barakova.anya@yandex.ru.

\section{Информация об авторах}

Алла Эдуардовна Калинина, доктор экономических наук, профессор, профессор кафедры прикладной информатики и математических методов в экономике, Волгоградский государственный университет, просп. Университетский, 100, 400062 г. Волгоград, Российская Федерация, allakalinina@volsu.ru.

Анна Сергеевна Баракова, студент института экономики и финансов, Волгоградский государственный университет, просп. Университетский, 100, 400062 г. Волгоград, Российская Федерация, barakova.anya@yandex.ru. 